\title{
Dynamic Phosphate Uptake in Arbuscular Mycorrhizal Roots Under Field Conditions
}

\author{
Yoshihiro Kobae* \\ Laboratory of Crop Nutrition, Department of Sustainable Agriculture, Rakuno Gakuen University, Ebetsu, Japan
}

Many crops are colonized with arbuscular mycorrhizal fungi (AMF), which can efficiently absorb nutrients such as phosphate from the soil. The utilization of mycorrhizal symbioses is one of the most promising options for developing resource-saving and sustainable agricultural systems. Most laboratory studies have illustrated the roles of AM symbiosis by inoculating plants with limited AMF isolates. In the field, however, the roots of crops are co-colonized with multiple AMF species, which are difficult to separate and identify and may have different abilities regarding phosphate uptake. In addition, it is difficult to understand which AMF are functional due to the dynamics of AMF colonization processes and the largely unknown genomic structure. This review summarizes key

OPEN ACCESS

Edited by:

Caroline Gutjahr,

Technische Universität München,

Germany

Reviewed by:

Natacha Bodenhausen,

Research Institute of Organic

Agriculture, Switzerland

Marcel Bucher,

Universität zu Köln, Germany

*Correspondence:

Yoshihiro Kobae

kobae@rakuno.ac.jp

Specialty section:

This article was submitted to

Soil Processes,

a section of the journal

Frontiers in Environmental Science

Received: 08 May 2018 Accepted: 18 December 2018

Published: 09 January 2019

Citation:

Kobae Y (2019) Dynamic Phosphate Uptake in Arbuscular Mycorrhizal

Roots Under Field Conditions.

Front. Environ. Sci. 6:159.

doi: 10.3389/fenvs.2018.00159 discoveries supporting the importance of the dynamics of AM colonization and genomic structure, which potentially influence the characteristics of AM phosphate uptake. Moreover, this review aims to identify the research direction necessary to obtain a better understanding of the phosphate uptake systems of crops in the field.

Keywords: arbuscular mycorrhizal fungi (AMF), colonization dynamics, indigenous AMF, infection unit, phosphate uptake

\section{INTRODUCTION}

To grow large amounts of crop biomass agricultural fields need to be fertilized because otherwise soils inevitably will become depleted of nutrients. However, excessive use of chemical fertilizer induces environmental pollution and promotes the depletion of natural resources (Fan et al., 2011). The nutrient uptake system of crops includes not only their unique transport system on the root epidermis but also a transport system mediated by specific soil microorganisms. However, the nutrient cycling arising in plant-microbial interaction is highly dynamic and complex associated with soil types, environmental changes, crop species, and cultivation management (Jacoby et al., 2017). Accordingly, a better understanding of the nutrient uptake system of crops in the field could help establish a resource saving and sustainable agricultural system.

Regarding the mobility of the inorganic nutrients that are essential for plants, that of phosphate in the soil is generally low and its absorption leads to the formation of depletion zones around the roots and rapidly limits its further uptake (Schachtman et al., 1998). Therefore, plants often suffer from phosphorus deficiency (Vance, 2001). To overcome this problem, plants have developed a wide array of phosphate uptake strategies, including biotic interactions with diverse soil microorganisms (Sharma et al., 2013). Among these interactions, symbiosis with arbuscular mycorrhizal fungi (AMF) in the roots is an ancient and ubiquitous relationship that began over 400 million years ago (Remy et al., 1994; Fonseca and Berbara, 2008). This symbiosis is observed 
in many economically important crops such as soybean, wheat, and corn. AMF hyphae growing outside roots allow plants to access phosphate further away from the root surface (Smith et al., 2011).

There are numerous AMF propagules in soil (e.g., spores, hyphae, and root remnants), and crop roots are commonly mycorrhizal (Sanders et al., 1996). As there are few soils with a complete absence of AMF in nature, the importance of mycorrhizal functioning (e.g., phosphate uptake) in crops is hardly noticeable (i.e., there is no mock control). Even if the plants are inoculated with AMF in the field, indigenous AMF in the soil are highly adapted to the local biotic and abiotic conditions and resistant to competition from novel AMF species (Hart et al., 2017). In fact, few studies have demonstrated the effectiveness of AMF inoculation under field conditions (Rodriguez and Sanders, 2015). Accordingly, to evaluate the ability of phosphate uptake by mycorrhizas, laboratory-scale potculture experiments involving the inoculation of a plant with one or more AMF isolates under AMF-free soil conditions have been conducted (Tawaraya, 2003; Deguchi et al., 2012). These studies clearly established that AMF mediate the phosphate uptake of plants and, in many cases, improve the nutrition and the productivity (Bucher, 2007).

Pot experiments with different AMF inoculations have shown that the level of plant phosphorus are different; thus the ability of mycorrhizal phosphate uptake may differ among AMF species (Smith and Smith, 2011; Walder and van der Heijden, 2015). At the same time, it has been established that mycorrhization is strongly suppressed under a high concentration of phosphate in soil (Baylis, 1967; Mosse, 1973), but the degree of this may differ among AMF and plant species (Johnson, 1993; Van Geel et al., 2016). Observations of mycorrhization processes at the cellular level revealed that AMF intracellular colonization was essentially transient, basically not synchronized among colonized cells, but roots stably interact with AMF (Gutjahr and Parniske, 2017), suggesting the dynamic nature of mycorrhization processes (i.e., physiologically/functionally active and inactive colonization can co-exist in the roots). It has been recently reported that the hyphal structure of AMF and fine root endophytes (Glomus tenue) in the roots rapidly changes over the course of a growing season associated with plant phenology and seasonal changes in the environment (Bueno de Mesquita et al., 2018). Accordingly, it is expected that the ability and stability of mycorrhizal phosphate uptake of crops under field conditions will change depending on several biotic and abiotic factors, although many of which are not experimentally validated. To utilize AM symbiosis to improve crop phosphorus nutrition, it is important to increase our basic knowledge of the colonization dynamics and the growth conditions under which the mycorrhizas express phosphate uptake activity associated with their symbiotic behavior.

This article reviews recent findings about phosphate uptake during mycorrhizal symbiosis from the perspective of AMF's highly dynamic colonization processes at the cellular level and the coexistence of genetically different AMF. Accordingly, this review attempts to bridge the gap between laboratory-level and field-level knowledge of the phosphate uptake mechanisms of mycorrhizal roots.

\section{CHALLENGES: DYNAMICS IN MYCORRHIZAL PHOSPHATE UPTAKE}

\section{Mycorrhizal Phosphate Uptake Pathway}

A specific morphological feature of AM symbiosis is the penetration of AMF into root cortical cells and the development of a highly branched hyphal structure called an arbuscule (Bonfante-Fasolo, 1984). Although AMF colonize inside root cells, they are not completely taken up as plant organelles because they are surrounded by periarbuscular membranes connected to the plasma membrane of plant cells (Harrison and Ivanov, 2017), indicating that AMF are localized outside the cells. As arbuscules are formed, the expression of host phosphate transporter genes is induced, which promotes phosphate uptake from the arbuscules (Pumplin et al., 2012). The expressed protein is specifically localized on the periarbuscular membrane (Harrison et al., 2002; Figure 1). In mutant plants carrying a deficient allele of these symbiotic phosphate transporter genes, an abnormally early degradation of the arbuscules along with reduction in the total phosphate uptake is observed (Javot et al., 2007; Yang et al., 2012; Willmann et al., 2013). This suggests a pivotal role of the phosphate transport system in the establishment of mycorrhizal roots. Besides the upregulation of the expression of symbiotic phosphate transporter genes and establishment of the "mycorrhizal pathway" of the phosphate uptake system in mycorrhizal plants, the expression of some phosphate transporter genes that are probably involved in the epidermal "direct pathway" of phosphate uptake is downregulated (Grunwald et al., 2009; Tamura et al., 2012; Yang et al., 2012). Accordingly, phosphate uptake can be dominated by the mycorrhizal pathway (Smith and Smith, 2011). Thus, the contribution of the direct pathway and the mycorrhizal pathway is not simply additive. More efforts are needed to investigate the mechanism that balances the contribution of these two pathways (Sawers et al., 2010; Smith and Smith, 2011; Chu et al., 2013; Facelli et al., 2014).

Benefits of AM symbiosis may not be provided without carbon cost (Sawers et al., 2017). The host plants must supply carbohydrates and lipids to AMF to support their growth (Rich et al., 2017; Roth and Paszkowski, 2017; Keymer and Gutjahr, 2018; Lanfranco et al., 2018), thereby maintaining a balance with the cost for the other metabolism. Recent studies have shown that the balance is influenced by plant genetic factors. A panel of 30 maize varieties was inoculated with Rhizophagus irregularis, a commonly used model AMF (Sawers et al., 2017). The levels of mycorrhizal phosphate uptake, plant and AMF biomass, and the accumulation of maize phosphate transporter gene transcripts varied among the maize varieties. An increase in biomass caused by mycorrhizal symbiosis is positively correlated with the level of mycorrhizal phosphate uptake and the amount of extraradical hyphae at least in the maize and $R$. irregularis interaction (Sawers et al., 2017). Additionally, the ionome of the same 30 maize varieties used in Sawers et al. (2017) revealed variety-specific responses to the colonization of Funneliformis mosseae in the concentration of some metal elements (Ramírez-Flores et al., 2017). These data clearly indicate that host genetic factors influence fungal growth strategy and have a great impact on 


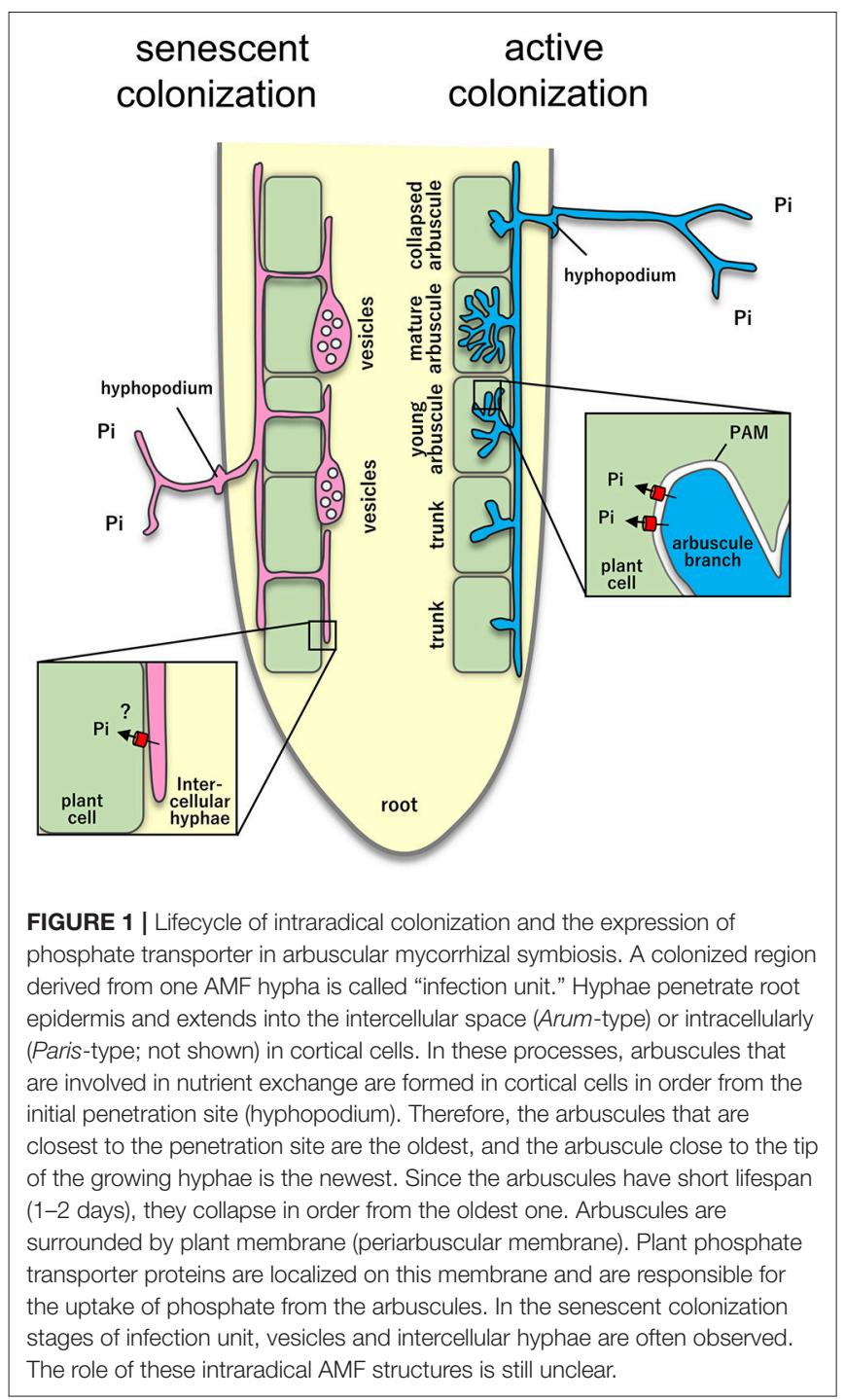

plant mycorrhiza-mediated mineral nutrition (Sawers et al., 2017).

A shift from the wild to cultivated species (domestication) may have decreased the ability of plants to positively respond to AMF (Lehmann et al., 2012; Sawers et al., 2018). Intensive breeding for high-input farming systems (i.e., intensive chemical fertilization) may have reduced the capacity of crops to gain maximum benefits from AM symbiosis. A recent study has investigated the response of 27 crop varieties compared with that of their wild progenitors to AM symbiosis (Martín-Robles et al., 2018). Among these varieties, the comparison of a subset of 14 pairs of wild and domesticated species revealed that the growth response of domesticated species to AM symbiosis was significantly reduced at high inorganic phosphate levels in the domesticated counterparts compared with that in their wild progenitors (Martín-Robles et al., 2018). This indicates the possibility that AM-independent nutrition and growth system of domesticated plants are related to high phosphate fertilization (Lanfranco et al., 2018).
High phosphate conditions significantly decrease the level of AMF colonization (Nagy et al., 2009; Balzergue et al., 2010; Breuillin et al., 2010). A recent study has shown that the supply of exogenous phosphate leads to a rapid $(<5 \mathrm{~h})$ suppression in arbuscule development and temporarily inhibits the growth of intraradical colonization (Kobae et al., 2016). Although transcriptomic analyses have failed to find any clear defense response of petunia plants during phosphate inhibition (Breuillin et al., 2010), recent QTL analyses using 94 bread wheat genotypes for root length colonization by a mixed inoculum of three AMF species have revealed at least two genetic loci related to defense and cell wall metabolism (Lehnert et al., 2017). It is hypothesized that defense mechanisms participate in limiting AMF colonization in plants cultivated in phosphorus-sufficient condition (Lehnert et al., 2017). One can speculate that a resistance mechanism to fungi has been selected in domesticated plants under high-input agriculture that led to a decrease of the activity or the contribution of mycorrhizal phosphate uptake pathway. However, based on the detected QTL, it is still unclear whether these genetic loci are functionally associated with mycorrhizal phosphate uptake (Lehnert et al., 2017). In the future, QTL mapping and further functional analyses such as RNAseq are needed to obtain more detailed information about the AM colonization of domesticated plants.

These recent studies have shown that crop varieties are one of the important biotic factors affecting the outcome of the inoculation of certain AMF strains. This suggests a difficulty of the utilization of AMF in agriculture, where crop varieties to be grown is determined depending on the local environment and economy and the AMF type in the soil is unclear. This does not mean that AMF function can be neglected. Most of the domesticated AMF-host crop species are inevitably colonized by native AMF community, where the effects of each colonization can be positive, neutral and negative (Johnson et al., 1997; Jones and Smith, 2004). The direct and mycorrhizal phosphateuptake pathway may be inadequately balanced in wheat and barley, leading to negative mycorrhizal responses (Smith and Smith, 2011). This is explained as due to a reduced direct phosphate uptake by colonization of AMF; however, mycorrhizal phosphate uptake inadequately compensates for direct phosphate uptake, although further analysis is needed. As mentioned previously, mutation of mycorrhizal phosphate transporter in the plant causes an inhibitory effect on AMF colonization (Javot et al., 2007; Yang et al., 2012; Willmann et al., 2013). A possible explanation for these observations is that the plant can assess the costs and the benefits (e.g., the favorable balance of phosphate-carbon exchange) in the interaction, and inhibits AM colonization if the balance is unfavorable (Nouri et al., 2014). Further analysis is needed whether such a balancing mechanism is conserved in domesticated plants.

High-input agriculture may have influenced not only plant traits but also AMF traits. For example, frequent soil disturbance (e.g., tillage) may act as a selection pressure for rapidly colonizing fungi, causing them to efficiently regenerate hyphal networks after disturbance and produce abundant spores (Niwa et al., 2018). These AMF traits possibly influence field crop nutrition. In future, it will be important to determine whether an adequate 
balance exists between the direct and mycorrhizal phosphateuptake pathway in field crops. For this, mycorrhizal phosphate uptake-defective mutant and wild-type plant pairs will be used to investigate the molecular mechanisms underlying the balance of direct/mycorrhizal phosphate uptake using radiolabeled phosphate (e.g., ${ }^{32}$ P; Jakobsen et al., 2001; Smith et al., 2004; Yang et al., 2012; Willmann et al., 2013) as a tracer using the soil of conventional agriculture (Rillig et al., 2008; Watts-Williams SJ Cavagnaro, 2015). The balance of mycorrhizal/direct phosphate uptake associated with indigenous AMF species also remains to be investigated.

\section{A Mosaic of AMF Is Responsible for Phosphate Uptake}

Inoculation of AMF can have a significant effect on plant phosphate uptake; however, there are many cases in which the phosphate uptake in inoculated plants does not increase compared with that of uninoculated plants (Tawaraya, 2003; Smith and Read, 2008). One reason for this is the potentially different level of mycorrhizal phosphate uptake among the types of AMF (Munkvold et al., 2004). Supporting this, the inoculation of Medicago sativa with more than 30 AMF types revealed that the performance of phosphate uptake differs markedly among AMF types (Mensah et al., 2015). In the field, roots are generally cocolonized with multiple AMF types (Kivlin et al., 2011). Strict host specificity, as found in plant-pathogenic fungi interaction, has not been recognized for the colonization of AMF except in mycoheterotrophic species (Redecker et al., 2003; Smith and Read, 2008). Accordingly, multiple AMF can co-colonize, overlap of individual AMF colonization in the roots and multiple AMF species have been detected in only a $1-\mathrm{cm}$-long root fragment (van Tuinen et al., 1998). Therefore, the ability of mycorrhizal roots to perform phosphate uptake in the field is assumed to be a mosaic of the different abilities of diverse AMF (Jansa et al., 2008); alternatively, only a portion of the AMF colonizing roots may temporarily contribute to phosphate uptake in response to specific environmental conditions (Compant et al., 2010).

As mycorrhizal phosphate uptake under the field condition may be achieved by the contribution of diverse AMF species colonizing the roots, it is crucially important to delimit species of AMF to obtain biological information about the mycorrhizas. To determine the biological type, the species of AMF should be generalized and described with "common language" (Öpik and Davison, 2016) to delimit and identify the AMF species among different studies. Unless AMF species in different fields are successfully delimited and classified with universal criteria, determining their phenotypes (e.g., phosphate uptake ability) in roots in a specific field will not be meaningful (Rosendahl, 2008).

Unfortunately, the morphology of intraradical mycelia is hardly distinguishable among the different AMF types, and different AMF physically overlap in the roots (Smith and Read, 2008); accordingly, the morphological identification of AMF species in mycorrhizal roots in the field is impossible. However, the advent of high-throughput sequencing methodologies has made it possible to characterize the co-colonization of genetically diverse AMF in roots in the field (Öpik et al., 2009). A total of
288 AMF species have been described (mostly delimited by their spore morphology), $\sim 60 \%$ of which have undergone sequencing of their nuclear ribosomal markers: small subunit (SSU) rRNA gene, ITS region, and large subunit (LSU) rRNA gene (Öpik and Davison, 2016). However, information about AMF assemblages obtained from DNA-based approaches can vary depending on the sample type, marker properties, sequencing approach, and choices made during bioinformatic analyses (Öpik et al., 2013; Hart et al., 2015; Varela-Cervero et al., 2015). The taxonomic resolution with at least SSU sequences, used in a well-maintained reference database for AMF (Öpik and Davison, 2016), is thought to be similar (i.e., at least at the genera level but not at the species or finer clade) to that of morphological delimitation (Davison et al., 2015). Importantly, however, the longer-read-length PacBio sequencing of the $R$. irregularis genome suggested the presence of intra-isolate variation in the rRNA genes (Maeda et al., 2018). Whether this variation is commonly observed in AMF and its biological effects are unclear; however, the finding suggests the need to re-evaluate the resolution power of commonly used DNA-based delimitation of AMF species. More importantly, most AMF in roots are thought to be unculturable or have not yet been cultured (Ohsowski et al., 2014). Fine endophyte, previously known as Glomus tenue, has been difficult to culture for a long time (Walker et al., 2018) but was proven not to be Glomus but was instead reclassified as Mucoromycotina (Orchard et al., 2017). Owing to the lack of reference nucleotide sequences of most AMF colonizing field roots and the current technical limitation in the robust delimitation of AMF species, we may have overlooked endemic cryptic AMF species in roots in the field (Rosendahl, 2008). The difficulties associated with defining AMF species have been reviewed in several review articles (Hibbett et al., 2016; Öpik and Davison, 2016; Sanders and Rodriguez, 2016; Selosse et al., 2016) and have recently been discussed in a workshop at the International Conference on Mycorrhiza (Bruns et al., 2017).

\section{The Nucleotide Sequence Does Not Necessarily Reflect the Functionality}

Despite the difficulty in the taxonomic characterization of AMF, high-throughput sequencing techniques can provide a comprehensive information of AMF genes in the roots. As information about the existence of AMF in roots accrues, questions related to the functional properties of individual AMF are receiving increasing attention (Lekberg and Koide, 2014; Öpik and Davison, 2016). A recently established approach designed for single-cell genomics and transcriptomics enables more high-throughput simultaneous analysis of many AMF species to discover the potential of the expression of their specific functions. Spore-based RNA sequencings were successfully applied to obtain transcript datasets from several AMF taxa, including genetically obscure genera such as Paraglomus, Ambispora, and Diversispora (Beaudet et al., 2018), highlighting their reproduction process, translation, amino acid metabolism, or energy production (Beaudet et al., 2018). However, not only quantitative evaluation of the "existence" of AMF nucleotide sequences but also evaluation of the hidden "dynamics" of the 
function in the mosaic of AMF might be necessary to accurately track the functionality of mycorrhizal roots (van der Heijden and Scheublin, 2007). This is because AMF colonization in roots has a short life cycle and some AMF may actively colonize while others may be inactive at a certain time point. Supporting this, not all intraradical mycelia derived from one hyphal colonization (infection unit) containing fine-branched arbuscules in roots grown in field soils are metabolically active (Kobae et al., 2017). Under specific environmental conditions, certain AMF may be deeply involved in host phosphate nutrition compared with others due to differing life cycles and biological characteristics. Thus, a list of AMF at a single time point can comprise the colonization of different contribution levels.

Detailed morphological studies of mycorrhization processes have suggested that arbuscule formation is basically transient (Gutjahr and Parniske, 2017), at least in the earliest developmental stages of mycorrhization (Kobae and Fujiwara, 2014). AMF hyphae penetrating root epidermal cells extend several millimeters in a longitudinal direction inside the root (Smith and Read, 2008). The extending intercellular hyphae successively form arbuscules inside cortical cells (Sanders and Sheikh, 1983). The lifespan of mature arbuscules that are accompanied by the expression of plant phosphate transporters is only a few days, which is followed by their immediate collapse (Kobae and Hata, 2010). Accordingly, the lifespan of active infection unit is probably within 1 week, at least in rice seedlings (Kobae and Fujiwara, 2014). It should be noted that some AMF species tend to produce vesicles in root areas with many senescent arbuscules (Kobae et al., 2016). Although the precise biological roles of vesicles remain unclear (Smith and Read, 2008), the protoplasm of vesicles contains nuclei, glycogen granules, small vacuoles, and lipid droplets (Bonfante-Fasolo, 1984). Given that the number of vesicles often increases in old or dead roots (Bonfante-Fasolo, 1984), vesicles are thought to be resting organs (Smith and Read, 2008). Moreover, roots are often colonized with intercellular hyphae without arbuscules (Figure 1). The role of intercellular hyphae and their lifespan are unknown (Smith and Read, 2008). As total phosphate uptake is largely reduced in plants with mutation of symbiotic phosphate transporter genes, intracellular colonization (arbuscule formation) most likely make a major contribution to mycorrhizal phosphate uptake, at least under laboratory conditions, with model plants and model AMF interaction. However, the life cycle and the functionalities of intraradical mycelia of native AMF have not been characterized.

To date, the cycle of intracellular colonization has rarely been taken into consideration when assessing the functionality of AMF via nucleotide information (genome and transcriptome) on the AMF that colonize roots, which includes both the active state and the inactive state of colonization. Because the colonization cycle is basically regulated in a cell-autonomous manner (Bucher et al., 2014), the functions of the mosaic of AMF in roots may not be synchronized. High-resolution analysis of the colonization process of individual AMF as well as their phosphate uptake ability will be necessary to obtain a better understanding of the mechanism of phosphate uptake by the mosaic of AMF. To this end, a new technique that enables tracking the dynamics of individual AMF colonization should be applied. This possibility will be mentioned in the last section.

\section{Role of Bacteria in Phosphate Uptake by AMF}

AMF can only utilize soluble inorganic phosphate. The majority of soil phosphate is present in an insoluble form because of immobilization and precipitation with other soil minerals and is, thus, poorly available for the plant. Phosphate solubilizing bacteria (PSB) are present in most soils and can potentially improve phosphate availability to the plant by solubilizing organic and inorganic phosphorus (Chen et al., 2006). Further, it has been shown in vitro that PSB solubilize phosphate via phosphatases, by lowering the soil $\mathrm{pH}$ and/or by chelating phosphate from soil minerals, such as iron and aluminum in acidic soils and calcium in alkaline soils, aided by organic acids (Rodriguez and Fraga, 1999; Browne et al., 2009). Recent studies have shown that the interaction of AMF with PSB in mycorrhizosphere also influences the mycorrhizal phosphate uptake. Ordoñez et al. (2016) investigated the influence of inoculation of Pseudomonas spp., which solubilizes tri-calcium phosphate in vitro, on AMF growth, root colonization, and plant phosphate uptake and revealed that AMF did not aid plant phosphate uptake in the presence of insoluble phosphate (rock phosphate) as the only phosphorus source, whereas PSB inoculation significantly aided the phosphate uptake. Interestingly, PSB inoculation strongly affected the growth of intra- and extra-radical hyphae of AMF (Ordoñez et al., 2016; Battini et al., 2017). Specifically, PSB enhanced metabolically active mycorrhizal colonization, measured as percentage root length colonized by AMF stained for phosphatase activity, even in unsterilized soil containing a native AMF and microbial communities (Ordoñez et al., 2016). Importantly, the in vitro ability of PSB in solubilizing insoluble phosphate was not a predictor of strains that result in improved phosphate acquisition by roots (Ordoñez et al., 2016). The strong effect exerted by PSB on the level of AMF colonization did not translate into obvious patterns of increased phosphate acquisition by plants, which was consistent with earlier findings (Smith et al., 2011). It is likely that AMF and PSB synergistically interact. However, such a biotic interaction under field conditions may be highly dynamic and complex (Ordoñez et al., 2016), and may include members of putative helper/antagonistic bacteria for AMF (Frey-Klett et al., 2007; Battini et al., 2017; Svenningsen et al., 2018).

One of the difficulties in the accurate detection of the occurrence of synergistic effects is deciphering the mechanistic basis of cooperative interaction. PSB involved in the solubilization of organic phosphates have been detected on the surface of AMF hyphae (Feng et al., 2002; Zhang et al., 2014). They thrive in close vicinity of AMF extraradical hyphae and intimately cooperate with AMF by providing inorganic minerals (e.g., phosphate) released from organic matter decomposition in exchange for carbon exuded by the hyphae (Zhang et al., 2016). Zhang et al. (2018) have reported the mechanism underlying the cooperative interaction of phosphate-carbon exchanges between $R$. irregularis and Rahnella aquatilis at the transcriptional level 
and demonstrated that fructose, glucose, and trehalose were exuded by the AMF hyphae. The transcript levels of fructose transporter and phosphatase genes of $R$. aquatilis increased $1 \mathrm{~h}$ after the presence of AMF hyphae. Treatment with $20 \mu \mathrm{M}$ fructose but not glucose (the approximate concentration detected in hyphal exudates) induced the expression of $R$. aquatilis phosphatase genes, indicating that the uptake of fructose by $R$. aquatilis triggered the expression of phosphataseencoding genes. They also demonstrated that acid and alkaline phosphatase activities in the culture medium increased in the presence of AMF hyphae, which then enhanced the solubilization of phytate phosphate. Finally, the transcript levels of the AMF phosphate transporter gene was increased in the presence of $R$. aquatilis. Given that bacteria can selectively use substrates from a mixture of different carbon sources (Görke and Stülke, 2008), the type of carbon exudates from AMF hyphae can change bacterial communities in the mycorrhizosphere (Zhang et al., 2018). In future, it will be important to study whether specific AMF families are associated with similar PSB communities or whether a change in PSB community can occur even in single AMF through various developmental stages of the host plant. In addition, the phosphate uptake, translocation, and export processes of AMF are important (Ezawa and Saito, 2018). The first identification of AMF phosphate transporter gene was reported in 1995 (Harrison and van Buuren, 1995). To date, several phosphate transporter genes have been isolated from AMF isolates and demonstrated that many of them expressed in both extraradical hyphae and intraradical hyphae, suggesting that they are involved in phosphate uptake from the soil, phosphate reabsorption from the periarbuscular space (Benedetto et al., 2005; Balestrini et al., 2007; Fiorilli et al., 2013) and phosphorus signal transduction (Xie et al., 2016). Molecular basis of these processes may be elucidated in model AMF using new genetic manipulation techniques (e.g., host-induced gene silencing, virus-induced gene silencing, and spray-induced gene silencing; Helber et al., 2011; Kikuchi et al., 2016; Xie et al., 2016; Wang and Jin, 2017). It is interesting to study whether the phosphate transport system of a model AMF is conserved in colonization of native AMF. A better understanding of phosphate homeostasis and translocation process of native AMF will further improve understanding regarding the function of the AMF-PSB interaction.

\section{Environmental Factors Influence Colonization Dynamics}

Among the environmental factors that influence the colonization of AMF in roots, the most intensely investigated is the level of phosphorus in the soil. It is well known that the AMF colonization level is remarkably decreased by the intense application of phosphorus fertilizer (Baylis, 1967; Mosse, 1973); this phenomenon is called "phosphate inhibition" (Graham et al., 1981). Rice seedlings that express the symbiotic phosphate transporter GFP (green fluorescent protein) fusion protein were infected with $R$. irregularis, treated with phosphate, and the colonization dynamics was examined by live imaging (Kobae et al., 2016). Mature arbuscules with fine branches were found to be resistant to phosphate treatment and their lifespan did not change compared with that of the control. However, the development of young arbuscules with insufficient branching was found to be severely suppressed in a short period, and the development of infection units was also suppressed. Eventually, overall mycorrhization temporarily stopped after the phosphate treatment, but the formation of a new infection unit began at least 2 days after treatment. Therefore, the functionality of AMF in roots is dynamically regulated according to phosphate availability in the soil. Importantly, phosphate inhibition induces the formation of vesicles of $R$. irregularis in rice roots by 1 day after phosphate treatment (Kobae et al., 2016), suggesting the resting state of intraradical colonization during phosphate inhibition. Moreover, the arbuscule/vesicle ratio varies depending on the AMF species even within the same subgenus Glomus Ab (Kiers et al., 2011); the genera Gigaspora and Scutellospora do not form intraradical vesicles (Smith and Read, 2008), suggesting the interspecific and intraspecific differences of resource hoarding strategies such as the morphological changes in high phosphate condition. Thus, the physiological status of intraradical colonization for individual AMF types and root cells along with the state of environmental factors (e.g., phosphate availability) should be clarified and taken into consideration when we assess the phosphate uptake of the mycorrhizas based on the nucleotide data from high-throughput sequencing studies.

\section{PERSPECTIVE: HOW DO WE KNOW ABOUT DYNAMIC MYCORRHIZAL PHOSPHATE UPTAKE?}

\section{Genetic Variability of AMF}

Our current knowledge about mycorrhizal phosphate uptake has largely been obtained through laboratory studies conducted on culturable AMF isolates, and we have a limited understanding of how diverse AMF members cooperatively or competitively influence phosphate uptake in the field (Burleigh et al., 2002; Engelmoer et al., 2014; van der Heijden et al., 2017). At present, high-throughput sequencing studies can produce metagenomic data for all AMF species in field samples. The drop in sequencing costs and the advances in informatics offer new opportunities for the reconstruction of individual microbial genomes (Parks et al., 2017), which may enable us to understand the genomic structures (e.g., genetic variations that can exist among nuclei or rRNA genes) of individual AMF and to more robustly define the species of AMF.

It is still unclear whether the genome of an individual AMF is stable. In other words, the definition of the species concept of AMF is enigmatic (Bruns et al., 2017). Early studies suggested that the AMF genomic structure is highly heterogeneous; in other words, their coenocytic mycelia and spores contain a mixture of thousands of genetically different nuclei, so they might be heterokaryons (Sanders and Croll, 2010). This is supported by the observation that, in laboratory in vitro studies, anastomosis (hyphal fusion) can occur between genetically different AMF types, suggesting the potential for genetic variability of AMF (Chagnon, 2014; Novais et al., 2017). However, in the fungal 
genetic system, the somatic incompatibility system usually triggers programmed cell death because nonself hyphal fusion is a risky endeavor that can rapidly disrupt cellular homeostasis (Strom and Bushley, 2016).

Recent advances in the genomic study of model AMF culture lines have suggested that these lines have a little genetic heterogeneity and the presence of sex genes (Tisserant et al., 2013; Lin et al., 2014; Ropars et al., 2016; Tang et al., 2016). This may lead to the acceptance of concepts of biological species (De Queiroz, 2005) in AMF as well as in many other organisms and to prediction of the phenotypic similarity within the same AMF species. Moreover, finding of the presence of intra-isolate heterologous rRNA genes may solve the problem of the complex genomic organization of AMF (Maeda et al., 2018). In addition, it is observed that isolates of the same AMF species undergo anastomosis and exchange nuclei (Croll et al., 2009; Sbrana et al., 2018). Based on the genome sequences of five $R$. irregularis isolates, it is also expected that they may undergo karyogamy, and eventually recombine through meiosis or parasexuality (Chen et al., 2018; Mathieu et al., 2018). More interestingly, Burkholderia endobacteria has a role in the reproductive biology of this host Rhizopus microsporus (Mucoromycotina) (PartidaMartinez et al., 2007; Torres-Cortés et al., 2015; Mondo et al., 2017). AMF also have the propensity to host diverse endobacteria (Bianciotto et al., 2003; Naito et al., 2017), suggesting the intriguing theoretical scenario that AMF endobactirea influence the genetic dynamics (Pawlowska et al., 2018). Accordingly, although many investigation is needed, in contrast to previous situation where there was little information underlying genetic heterogeneity, the genetics of model AMF may be easier to understand than previously thought, and the genetic control and utilization of the specific functional traits of AMF in the field may become possible. However, some researchers still suggest that natural AMF may have genetic heterogeneity (Sanders and Croll, 2010; Bruns et al., 2017). In fact, sister spores generated from the anastomosis between different AMF isolates were shown to have different influences on the growth of the host plants (Croll et al., 2009; Angelard et al., 2010). Study of the genetics of AMF is still in its infancy. It is thus still unclear whether the situation described in laboratory-cultured lines can be generalized in AMF including unknown natural species.

In the field, mycorrhizae of conspecific AMF are thought to be connected with common mycorrhizal networks (CMNs; Bücking et al., 2016). A CMN shares cellular constituents including nucleus, organelles, viruses, and endobacteria in the same cytoplasm of coenocytic mycelia (Jany and Pawlowska, 2010). If it is true that the genotype and phenotype of AMF mycelia can change rapidly in response to environmental changes (e.g., host plant; Angelard et al., 2014), it is reasonable to think that some portion of CMN terminal branches may change their genetic and functional traits by encountering different biotic (host species, microbiome) and abiotic (nutrient status, cultivation management, soil properties) stimuli during their colonization process. In this case, CMN may not be genetically homogeneous and may be heterogeneous over time, suggesting the potential impact of genetic variation from the perspective of long-term and field-level cultivation (Vályi et al., 2016). To obtain a better understanding of AMF genetic variability under field conditions, continuous observation of the genomic structure of $\mathrm{AMF}$ at a fixed point in soil will be important. Especially, it will be important to investigate whether and how crop species, crop rotation, field management, and fertilization affect the genomes and the functionality of individual AMF.

\section{Colonization Dynamics}

Arbuscules are thought to be the parts essential for phosphate uptake because symbiotic phosphate transporter proteins are specifically expressed and localized in arbuscule-containing cells and their mutation causes a reduction of mycorrhizal phosphate uptake ability (Gutjahr and Parniske, 2017). However, most of our understanding of the phosphate uptake at arbuscules is based on recent studies analyzing the associations between model plant species and culturable AMF. Because all unculturable AMF that colonize roots grown under field conditions have not been experimentally characterized, there is the unsatisfactory situation that the phosphate uptake of field mycorrhizas can only be interpreted with the current knowledge of AM symbiosis. Recent studies on the lifecycle of intracellular colonization and its dynamic environmental responses (e.g., phosphate inhibition, vesicle formation) suggest that the colonization dynamics may affect the phosphate uptake ability of mycorrhizal roots. However, it is unclear whether such colonization dynamics observed in model systems is a general phenomenon in AMF in the field. For example, some AMF extend intercellular hyphae during the development of an infection unit (Arum type) and others extend their intraradical hyphae by penetrating root cortical cells (Paris type; Smith and Read, 2008). The former type is probably able to rapidly withdraw from plant cells after the collapse of arbuscule branches Kobae and Hata, 2010, but it is unknown whether the latter's intracellular hyphal coil (Dickson et al., 2007) can withdraw from plant cells. Are there differences in the strategy of nutrient exchange between these groups? Since the biology and even the colonization processes of culturable AMF have yet to be fully characterized, the characteristics of field AMF, which are not cultured, are completely unknown.

To date, few groups have conducted colonization dynamicsbased functional studies. This is probably because we still do not have suitable molecular or histological tools to detect and analyze the lifecycle of colonization. Interestingly, Floss et al. (2017) recently demonstrated that a transcription factor of Medicago truncatula, MYB1, is a central regulator of arbuscule degeneration. MYB1 regulates the expression of a number of genes encoding digesting hydrolytic enzymes such as chitinase, lipase, and proteases, which are likely candidate markers, using it simultaneously with a symbiotic phosphate transporter, precisely reflecting the lifecycle of colonization. Next, it will be important to investigate the colonization dynamics of unculturable AMF colonizing field roots using new molecular markers or techniques.

As mentioned above, mycorrhizae can be regarded as a mosaic of diverse AMF individuals in symbiosis with the root. Because the individual AMF in the roots are the pieces of the puzzle of the functionality of field mycorrhizae, the need 
to explore the functioning of AMF in situ and at the singlecell level has been pointed out (Limpens and Geurts, 2014; Öpik and Davison, 2016; Taylor et al., 2017; van der Heijden et al., 2017). In particular, genetic and functional analyses of infection units in roots grown in the field might be a major frontier for understanding the biology of field AMF and their functionality. Recently, a new technique for elucidating the rRNA gene information of metabolically active infection units has been reported (Kobae et al., 2016). Root segments ( $<3 \mathrm{~mm}$ ) of rice containing an active infection unit were dissected and squashed, large subunit rRNA genes were amplified using fungal universal primers and the sequences were directly determined by Sanger sequencing. By combining this method with the latest singlecell-level, ultra-low input micro-transcriptome analysis (Beaudet et al., 2018) coupled with the reconstruction of genomes of each infection unit, we should be able to increase our basic knowledge of the genetics of AMF, mycorrhization processes by tracing specific AMF (Schlaeppi et al., 2016), and the expression of functionality. In this approach, fluorescent marker plants (e.g., phosphate transporter-GFP rice; Kobae and Hata, 2010) would be feasible for efficiently detecting the functional colonization.

On the other hand, AMF functioning may be influenced by interacting microorganisms (e.g., PSB). These interactions will be partly characterized by the studies of molecular dialogues with fungal/bacterial effectors (Sedzielewska Toro, 2016; Kamel et al., 2017), plant hormones (Sawers et al., 2018), expression of nutrient transporters and metabolic crosstalk among symbionts (Lanfranco et al., 2018). As mentioned above, mycorrhizal phosphate uptake in the field is assumed to be driven by the mosaic of different AMF. The combined investigation of colonization dynamics and high-resolution functional cross-talk among symbionts presents a logical next step for the better

\section{REFERENCES}

Angelard, C., Colard, A., Niculita-Hirzel, H., Croll, D., and Sanders, I. R. (2010). Segregation in a mycorrhizal fungus alters rice growth and symbiosis-specific gene transcription. Curr. Biol. 20, 1216-1221. doi: 10.1016/j.cub.2010.05.031

Angelard, C., Tanner, C. J., Fontanillas, P., Niculita-Hirzel, H., Masclaux, F., and Sanders, I. R. (2014). Rapid genotypic change and plasticity in arbuscular mycorrhizal fungi is caused by a host shift and enhanced by segregation. ISME J. 8, 284-294. doi: 10.1038/ismej.2013.154

Balestrini, R., Gómez-Ariza, J., Lanfranco, L., and Bonfante, P. (2007). Laser microdissection reveals that transcripts for five plant and one fungal phosphate transporter genes are contemporaneously present in arbusculated cells. Mol. Plant Microbe Interact. 20, 1055-1062. doi: 10.1094/MPMI-20-9-1055

Balzergue, C., Puech-Pagès, V., Bécard, G., and Rochange, S. F. (2010). The regulation of arbuscular mycorrhizal symbiosis by phosphate in pea involves early and systemic signalling events. J. Exp. Bot. 62, 1049-1060. doi: $10.1093 /$ jxb/erq335

Battini, F., Grønlund, M., Agnolucci, M., Giovannetti, M., and Jakobsen, I. (2017). Facilitation of phosphorus uptake in maize plants by mycorrhizosphere bacteria. Sci. Rep. 7:4686. doi: 10.1038/s41598-017-04959-0

Baylis, G. T. S. (1967). Experiments on the ecological significance of phycomycetous mycorrhizas. New Phytol. 66, 231-243. doi: 10.1111/j.1469-8137.1967.tb06001.x

Beaudet, D., Chen, E. C. H., Mathieu, S., Yildirir, G., Ndikumana, S., Dalpé Y., et al. (2018). Ultra-low input transcriptomics reveal the spore functional content and understanding of the mechanism of mycorrhizal phosphate uptake.

\section{CONCLUSION}

In field, the roots of crops are co-colonized with multiple AMF species, which are difficult to separate and identify. The ability of mycorrhizal roots to perform phosphate uptake in the field is assumed to be a mosaic of the different abilities of diverse AMF. However, the biology of uncultured AMF in the field is hardly understood. Given advances in high-throughput sequencing technologies, such complex phosphate uptake systems under field conditions are the new frontier in mycorrhizal research and are crucial for managing the phosphate nutrition of crops. To this end, the understanding of the dynamics of colonization and the genetics of field AMF coupled with their functionality will be important. Many economically important crops (e.g., maize, soybean, wheat, and barley) are commonly mycorrhizal and their nutrition is influenced by the biology of AMF. Accordingly, a better understanding of the mineral nutrient uptake systems of crop mycorrhizas in the field could help establish a resourcesaving and sustainable agricultural system.

\section{AUTHOR CONTRIBUTIONS}

The author confirms being the sole contributor of this work and has approved it for publication.

\section{FUNDING}

This work was supported partly by ACCEL from the Japan Science and Technology Agency (grant number JPMJAC1403). phylogenetic affiliations of poorly studied arbuscular mycorrhizal fungi. DNA Res. 25, 217-227. doi: 10.1093/dnares/dsx051

Benedetto, A., Magurno, F., Bonfante, P., and Lanfranco, L. (2005). Expression profiles of a phosphate transporter gene (GmosPT) from the endomycorrhizal fungus Glomus mosseae. Mycorrhiza 15, 620-627. doi: 10.1007/s00572-005-0006-9

Bianciotto, V., Lumini, E., Bonfante, P., and Vandamme, P. (2003). 'Candidatus Glomeribacter gigasporarum' gen. nov., sp nov., an endosymbiont of arbuscular mycorrhizal fungi. Int. J. Syst. Evol. Microbiol. 53, 121-124. doi: 10.1099/ijs.0.02382-0

Bonfante-Fasolo, P. (1984). "Anatomy and morphology of VA mycorrhizae," in VA Mycorrhizas, eds C. L. Powell and D. J. Bagyaraj (Boca Raton, FL: CRC Press), $5-33$.

Breuillin, F., Schramm, J., Hajirezaei, M., Ahkami, A., Favre, P., Druege, U., et al. (2010). Phosphate systemically inhibits development of arbuscular mycorrhiza in Petunia hybrida and represses genes involved in mycorrhizal functioning. Plant J. 64, 1002-1017. doi: 10.1111/j.1365-313X.2010.04385.x

Browne, P., Rice, O., Miller, S. H., Burke, J., Dowling, D. V., Morrissey, J. P., et al. (2009). Superior inorganic phosphate solubilization is linked to phylogeny within the Pseudomonas fluorescens complex. Appl. Soil Ecol. 43, 131-138. doi: 10.1016/j.apsoil.2009. 06.010

Bruns, T. D., Corradi, N., Redecker, D., and Taylor, J. W., Öpik, M. (2017). Glomeromycotina: what is a species and why should we care? New Phytol. 220, 963-967. doi: 10.1111/nph.14913 
Bucher, M. (2007). Functional biology of plant phosphate uptake at root and mycorrhiza interfaces. New Phytol. 173, 11-26 doi: 10.1111/j.1469-8137.2006.01935.x

Bucher, M., Hause, B., Krajinski, F., and Küster, H. (2014). Through the doors of perception to function in arbuscular mycorrhizal symbioses. New Phytol. 204, 833-840. doi: 10.1111/nph.12862

Bücking, H., Mensah, J. A., and Fellbaum, C. R. (2016). Common mycorrhizal networks and their effect on the bargaining power of the fungal partner in the arbuscular mycorrhizal symbiosis. Commun. Integr. Biol. 9:e1107684. doi: $10.1080 / 19420889.2015 .1107684$

Bueno de Mesquita, C. P., Martinez Del Río, C. M., Suding, K. N., and Schmidt, S. K. (2018). Rapid temporal changes in root colonization by arbuscular mycorrhizal fungi and fine root endophytes, not dark septate endophytes, track plant activity and environment in an alpine ecosystem. Mycorrhiza 28, 717-726. doi: 10.1007/s00572-018-0863-7

Burleigh, S. H., Cavagnaro, T., and Jakobsen, I. (2002). Functional diversity of arbuscular mycorrhizas extends to the expression of plant genes involved in P nutrition. J. Exp. Bot. 53, 1593-1601. doi: 10.1093/jxb/erf013

Chagnon, P. L. (2014). Ecological and evolutionary implications of hyphal anastomosis in arbuscular mycorrhizal fungi. FEMS Microbiol. Ecol. 88, 437-444. doi: 10.1111/1574-6941.12321

Chen, E. C. H., Morin, E., Beaudet, D., Noel, J., Yildirir, G., Ndikumana, S., et al. (2018). High intraspecifc genome diversity in the model arbuscular mycorrhizal symbiont Rhizophagus irregularis. New Phytol. 220, 1161-1171. doi: $10.1111 /$ nph.14989

Chen, Y. P., Rekha, P. D., Arun, A. B., Shen, F. T., Lai, W. A., and Young, C. C. (2006). Phosphate solubilizing bacteria from subtropical soil and their tricalcium phosphate solubilizing abilities. Appl. Soil Ecol. 34, 33-41. doi: 10.1016/j.apsoil.2005.12.002

Chu, Q., Wang, X., Yang, Y., Chen, F., Zhang, F., and Feng, G. (2013). Mycorrhizal responsiveness of maize (Zea mays L.) genotypes as related to releasing date and available $\mathrm{P}$ content in soil. Mycorrhiza 23, 497-505. doi: 10.1007/s00572-013-0492-0

Compant, S., van der Heijden, M. G., and Sessitsch, A. (2010). Climate change effects on beneficial plant-microorganism interactions. FEMS Microbiol. Ecol. 73, 197-214. doi: 10.1111/j.1574-6941.2010.00900.x

Croll, D., Giovannetti, M., Koch, A. M., Sbrana, C., Ehinger, M., Lammers, P. J., et al. (2009). Nonself vegetative fusion and genetic exchange in the arbuscular mycorrhizal fungus Glomus intraradices. New Phytol. 181, 924-937. doi: $10.1111 / j .1469-8137.2008 .02726 . x$

Davison, J., Moora, M., Öpik, M., Adholeya, A., and Ainsaar, L., Bâ, A. et al. (2015). Global assessment of arbuscular mycorrhizal fungus diversity reveals very low endemism. Science 349, 970-973. doi: 10.1126/science.aab1161

de Queiroz, K. (2005). Ernst Mayr and the modern concept of species. Proc. Natl. Acad. Sci. U.S.A. 102, 6600-6607. doi: 10.1073/pnas.0502030102

Deguchi, S., Uozumi, S., Touno, E., Kaneko, M., and Tawaraya, K. (2012). Arbuscular mycorrhizal colonization increases phosphorus uptake and growth of corn in a white clover living mulch system. Soil Sci. Plant Nutr. 58, 169-172. doi: 10.1080/00380768.2012.6 62697

Dickson, S., Smith, F. A., and Smith, S. E. (2007). Structural differences in arbuscular mycorrhizal symbioses: more than 100 years after Gallaud, where next? Mycorrhiza 17, 375-393. doi: 10.1007/s00572-007-0130-9

Engelmoer, D. J., Behm, J. E., and Toby Kiers, E. (2014). Intense competition between arbuscular mycorrhizal mutualists in an in vitro root microbiome negatively affects total fungal abundance. Mol. Ecol. 23, 1584-1593. doi: $10.1111 / \mathrm{mec} .12451$

Ezawa, T., and Saito, K. (2018). How do arbuscular mycorrhizal fungi handle phosphate? New insight into fine-tuning of phosphate metabolism. New Phytol. 220, 1116-1121. doi: 10. 1111/nph.15187

Facelli, E., Duan, T., Smith, S. E., Christophersen, H. M., Facelli, J. M., and Smith, F. A. (2014). Opening the black box: outcomes of interactions between arbuscular mycorrhizal (AM) and non-host genotypes of Medicago depend on fungal identity, interplay between $\mathrm{P}$ uptake pathways and external P supply. Plant Cell. Environ. 37, 1382-1392. doi: 10.1111/pce.12237

Fan, M., Shen, J., Yuan, L., Jiang, R., Chen, X., Davies, W. J., et al. (2011). Improving crop productivity and resource use efficiency to ensure food security and environmental quality in China. J Exp. Bot. 63, 13-24. doi: 10.1093/jxb/err248
Feng, G., Su, Y. B., Li, X. L., Wang, H., Zhang, F. S., Tang, C. X., et al. (2002). Histochemical visualization of phosphatase released by arbuscular mycorrhizal fungi in soil. J. Plant Nutr. 25, 969-980. doi: 10.1081/PLN-120003932

Fiorilli, V., Lanfranco, L., and Bonfante, P. (2013). The expression of GintPT, the phosphate transporter of Rhizophagus irregularis, depends on the symbiotic status and phosphate availability. Planta 237, 1267-1277. doi: $10.1007 / \mathrm{s} 00425-013-1842-\mathrm{z}$

Floss, D. S., Gomez, S. K., Park, H. J., MacLean, A. M., Müller, L. M., Bhattarai, K. K., et al. (2017). A transcriptional program for arbuscule degeneration during AM symbiosis is regulated by MYB1. Curr. Biol. 27, 1206-1212. doi: 10.1016/j.cub.2017.03.003

Fonseca, H. M., and Berbara, R. L. (2008). Does Lunularia cruciata form symbiotic relationships with either Glomus proliferum or G. Intraradices? Mycol. Res. 112, 1063-1068. doi: 10.1016/j.mycres.2008.03.008

Frey-Klett, P., Garbaye, J. A., and Tarkka, M. (2007). The mycorrhiza helper bacteria revisited. New Phytol. 176, 22-36. doi: 10.1111/j.1469-8137.2007.02191.x

Görke, B., and Stülke, J. (2008). Carbon catabolite repression in bacteria: many ways to make the most out of nutrients. Nat Rev Microbiol. 6:613 doi: $10.1038 / \mathrm{nrmicro} 1932$

Graham, J. H., Leonard, R. T., and Menge, J. A. (1981). Membranemediated decrease in root exudation responsible for phorphorus inhibition of vesicular arbuscular mycorrhiza formation. Plant Physiol. 68, 548-552. doi: $10.1104 / p p \cdot 68.3 .548$

Grunwald, U., Guo, W., Fischer, K., Isayenkov, S., Ludwig-Müller, J., Hause, B., et al. (2009). Overlapping expression patterns and differential transcript levels of phosphate transporter genes in arbuscular mycorrhizal, Pi-fertilised and phytohormone-treated Medicago truncatula roots. Planta 229, 1023-1034. doi: $10.1007 / \mathrm{s} 00425-008-0877-\mathrm{z}$

Gutjahr, C., and Parniske, M. (2017). Control of partner lifetime in a plant-fungus relationship. Curr. Biol. 27, R420-R423. doi: 10.1016/j.cub.2017.04.020

Harrison, M. J., Dewbre, G. R., and Liu, J. (2002). A phosphate transporter from Medicago truncatula involved in the acquisition of phosphate released by arbuscular mycorrhizal fungi. Plant Cell 14, 2413-2429. doi: $10.1105 /$ tpc. 004861

Harrison, M. J., and Ivanov, S. (2017). Exocytosis for endosymbiosis: membrane trafficking pathways for development of symbiotic membrane compartments. Curr. Opin. Plant Biol. 38, 101-108. doi: 10.1016/j.pbi.2017.04.019

Harrison, M. J., and van Buuren, M. L. (1995). A phosphate transporter from the mycorrhizal fungus Glomus versiforme. Nature 378, 626-629. doi: $10.1038 / 378626 \mathrm{a} 0$

Hart, M. M., Aleklett, K., Chagnon, P. L., Egan, C., Ghignone, S., Helgason, T., et al. (2015). Navigating the labyrinth: a guide to sequence-based, community ecology of arbuscular mycorrhizal fungi. New Phytol. 207, 235-247. doi: $10.1111 / \mathrm{nph} .13340$

Hart, M. M., Antunes, P. M., Chaudhary, V. B., and Abbott, L. K. (2017). Fungal inoculants in the field: is the reward greater than the risk? Funct. Ecol. 32, 126-135. doi: 10.1111/1365-2435.12976

Helber, N., Wippel, K., Sauer, N., Schaarschmidt, S., Hause, B., and Requena, N. (2011). A versatile monosaccharide transporter that operates in the arbuscular mycorrhizal fungus Glomus sp. is crucial for the symbiotic relationship with plants. Plant Cell 23, 3812-3823. doi: 10.1105/tpc.111.089813

Hibbett, D., Abarenkov, K., Kõljalg, U., Öpik, M., and Chai, B., Cole J et al (2016). Sequence-based classification and identification of Fungi. Mycologia 108, 1049-1068. doi: 10.3852/16-130

Jacoby, R., Peukert, M., Succurro, A., Koprivova, A., and Kopriva, S. (2017). The role of soil microorganisms in plant mineral nutrition-current knowledge and future directions. Front. Plant Sci. 8:1617. doi: 10.3389/fpls.2017. 01617

Jakobsen, I., Gazey, C., and Abbott, L. K. (2001). Phosphate transport by communities of arbuscular mycorrhizal fungi in intact soil cores. New Phytol. 149, 95-103. doi: 10.1046/j.1469-8137.2001.00006.x

Jansa, J., Smith, F. A., and Smith, S. E. (2008). Are there benefits of simultaneous root colonization by different arbuscular mycorrhizal fungi? New Phytol. 177, 779-789. doi: 10.1111/j.1469-8137.2007.02294.x

Jany, J. L., and Pawlowska, T. E. (2010). Multinucleate spores contribute to evolutionary longevity of asexual Glomeromycota. Am. Nat. 175, 424-435. doi: $10.1086 / 650725$ 
Javot, H., Pumplin, N., and Harrison, M. J. (2007). Phosphate in the arbuscular mycorrhizal symbiosis: transport properties and regulatory roles. Plant Cell Environ. 30, 310-322. doi: 10.1111/j.1365-3040.2006.01617.x

Johnson, N. C. (1993). Can fertilization of soil select less mutualistic mycorrhizae? Ecol. Appl. 3, 749-757. doi: 10.2307/1942106

Johnson, N. C., Graham, J. H., and Smith, F. A. (1997). Functioning of mycorrhizal associations along the mutualism-parasitism continuum. New Phytol. 135, 575-586. doi: 10.1046/j.1469-8137.1997.00729.x

Jones, M. D., and Smith, S. E. (2004). Exploring functional definitions of mycorrhizas: are mycorrhizas always mutualisms? Can. J. Bot. 82, 1089-1109. doi: 10.1139/b04-110

Kamel, L., Tang, N., Malbreil, M., San Clemente, H., Le Marquer, M., Roux, C., et al. (2017). The comparison of expressed candidate secreted proteins from two arbuscular mycorrhizal fungi unravels common and specific molecular tools to invade different host plants. Front. Plant Sci. 8:124. doi: $10.3389 /$ fpls.2017.00124

Keymer, A., and Gutjahr, C. (2018). Cross-kingdom lipid transfer in arbuscular mycorrhiza symbiosis and beyond. Curr. Opin. Plant Biol. 44, 137-144. doi: 10.1016/j.pbi.2018.04.005

Kiers, E. T., Duhamel, M., Beesetty, Y., Mensah, J. A., Franken, O., Verbruggen, E., et al. (2011). Reciprocal rewards stabilize cooperation in the mycorrhizal symbiosis. Science 333, 880-882. doi: 10.1126/science. 1208473

Kikuchi, Y., Hijikata, N., Ohtomo, R., Handa, Y., Kawaguchi, M., Saito, K., et al. (2016). Aquaporin-mediated long-distance polyphosphate translocation directed towards the host in arbuscular mycorrhizal symbiosis: application of virus-induced gene silencing. New Phytol. 211, 1202-1208. doi: $10.1111 /$ nph. 14016

Kivlin, S. N., Hawkes, C. V., and Treseder, K. K. (2011). Global diversity and distribution of arbuscular mycorrhizal fungi. Soil. Biol. Biochem. 43, 2294-2303. doi: 10.1016/j.soilbio.2011.07.012

Kobae, Y., and Fujiwara, T. (2014). Earliest colonization events of Rhizophagus irregularis in rice roots occur preferentially in previously uncolonized cells. Plant Cell Physiol. 55, 1497-1510. doi: 10.1093/pcp/pcu081

Kobae, Y., and Hata, S. (2010). Dynamics of periarbuscular membranes visualized with a fluorescent phosphate transporter in arbuscular mycorrhizal roots of rice. Plant Cell Physiol. 51, 341-353. doi: 10.1093/pcp/ pcq013

Kobae, Y., Ohmori, Y., Saito, C., Yano, K., Ohtomo, R., and Fujiwara, T. (2016). Phosphate treatment strongly inhibits new arbuscule development but not the maintenance of arbuscule in mycorrhizal rice roots. Plant Physiol. 171, 566-579. doi: 10.1104/pp.16.00127

Kobae, Y., Ohtomo, R., Oka, N., and Morimoto, S. (2017). A simple model system for identifying arbuscular mycorrhizal fungal taxa that actively colonize rice roots grown in field soil. Soil Sci. Plant Nutr. 63, 29-36. doi: 10.1080/00380768.2016.1277156

Lanfranco, L., Fiorilli, V., and Gutjahr, C. (2018). Partner communication and role of nutrients in the arbuscular mycorrhizal symbiosis. New Phytol. 220, 1031-1046. doi: 10.1111/nph.15230.

Lehmann, A., Barto, E. K., Powell, J. R., and Rillig, M. C. (2012). Mycorrhizal responsiveness trends in annual crop plants and their wild relatives a meta-analysis on studies from 1981 to 2010. Plant Soil 355, 231-250. doi: 10.1007/s11104-011-1095-1

Lehnert, H., Serfling, A., Enders, M., Friedt, W., and Ordon, F. (2017). Genetics of mycorrhizal symbiosis in winter wheat (Triticum aestivum). New Phytol. 215, 779-791. doi: 10.1111/nph.14595

Lekberg, Y., and Koide, R. T. (2014). Integrating physiological, community and evolutionary perspectives of the arbuscular mycorrhizal symbiosis. Botany 92 , 241-251. doi: 10.1139/cjb-2013-0182

Limpens, E., and Geurts, R. (2014). Plant-driven genome selection of arbuscular mycorrhizal fungi. Mol. Plant Pathol. 15, 531-534. doi: 10.1111/mpp.12149

Lin, K., Limpens, E., Zhang, Z., Ivanov, S., Saunders, D. G., Mu, D., et al. (2014). Single nucleus genome sequencing reveals high similarity among nuclei of an endomycorrhizal fungus. PLoS Genet. 10:e1004078. doi: 10.1371/journal.pgen.1004078

Maeda, T., Kobayashi, Y., Kameoka, H., Okuma, N., Takeda, N., Yamaguchi, K., et al. (2018). Evidence of non-tandemly repeated rDNAs and their intragenomic heterogeneity in Rhizophagus irregularis. Commun. Biol. 1:87. doi: 10.1038/s42003-018-0094-7
Martín-Robles, N., Lehmann, A., Seco, E., Aroca, R., Rillig, M. C., and Milla, R. (2018). Impacts of domestication on the arbuscular mycorrhizal symbiosis of 27 crop species. New Phytol. 218, 322-334. doi: 10.1111/nph.14962

Mathieu, S., Cusant, L., Roux, C., and Corradi, N. (2018). Arbuscular mycorrhizal fungi: intraspecific diversity and pangenomes. New Phytol. 220, 1129-1134. doi: $10.1111 / \mathrm{nph} .15275$

Mensah, J. A., Koch, A. M., Antunes, P. M., Hart, M. M., Kiers, E. T., and Bücking, H. (2015). High functional diversity within arbuscular mycorrhizal fungal species is associated with differences in phosphate and nitrogen uptake and fungal phosphate metabolism. Mycorrhiza 25, 533-546. doi: 10.1007/s00572-015-0631-x

Mondo, S. J., Lastovetsky, O. A., Gaspar, M. L., Schwardt, N. H., Barber, C. C., Riley, R., et al. (2017). Bacterial endosymbionts influence host sexuality and reveal reproductive genes of early divergent fungi. Nat. Commun. 8:1843. doi: 10.1038/s41467-017-02052-8

Mosse, B. (1973). Plant growth responses to vesicular-arbuscular mycorrhiza IV. in soil given additional phosphate. New Phytol. 72, 127-136. doi: 10.1111/j.1469-8137.1973.tb02017.x

Munkvold, L., Kjøller, R., Vestberg, M., Rosendahl, S., and Jakobsen, I. (2004). High functional diversity within species of arbuscular mycorrhizal fungi. New Phytol. 164, 357-364. doi: 10.1111/j.1469-8137.2004.01169.x

Nagy, R., Drissner, D., Amrhein, N., Jakobsen, I., and Bucher, M. (2009). Mycorrhizal phosphate uptake pathway in tomato is phosphorusrepressible and transcriptionally regulated. New Phytol. 181, 950-959. doi: 10.1111/j.1469-8137.2008.02721.x

Naito, M., Desirò, A., González, J. B., Tao, G., Morton, J. B., Bonfante, P., et al. (2017). 'Candidatus Moeniiplasma glomeromycotorum', an endobacterium of arbuscular mycorrhizal fungi. Int. J. Syst. Evol. Microbiol. 67, 1177-1184. doi: 10.1099/ijsem.0.001785

Niwa, R., Koyama, T., Sato, T., Adachi, K., Tawaraya, K., Sato, S., et al. (2018). Dissection of niche competition between introduced and indigenous arbuscular mycorrhizal fungi with respect to soybean yield responses. Sci. Rep. 8:7419. doi: 10.1038/s41598-018-25701-4

Nouri, E., Breuillin-Sessoms, F., Feller, U., and Reinhardt, D. (2014). Phosphorus and nitrogen regulate arbuscular mycorrhizal symbiosis in Petunia hybrida. PLoS ONE 9:e90841. doi: 10.1371/journal.pone.0090841

Novais, C. B. D., Pepe, A., Siqueira, J. O., Giovannetti, M., and Sbrana, C. (2017). Compatibility and incompatibility in hyphal anastomosis of arbuscular mycorrhizal fungi. Sci. Agricola 74, 411-416. doi: 10.1590/1678-992x-2016-0243

Ohsowski, B. M., Zaitsoff, P. D., and Opik, M., Hart, M. M. (2014). Where the wild things are: looking for uncultured Glomeromycota. New Phytol. 204, 171-179. doi: $10.1111 /$ nph.12894

Öpik, M., Davison, J. (2016). Uniting species- and community-oriented approaches to understand arbuscular mycorrhizal fungal diversity. Fungal Ecol. 24, 106-113. doi: 10.1016/j.funeco.2016.07.005

Öpik, M., Davison, J., and Moora, M., Zobel, M. (2013). DNA-based detection and identification of Glomeromycota: the virtual taxonomy of environmental sequences. Botany 92, 135-147. doi: 10.1139/cjb-201 3-0110

Opik, M., Metsis, M., Daniell, T. J., and Zobel, M., Moora, M. (2009). Largescale parallel 454 sequencing reveals host ecological group specificity of arbuscular mycorrhizal fungi in a boreonemoral forest. New Phytol. 184, 424-437. doi: 10.1111/j.1469-8137.2009.02920.x

Orchard, S., Standish, R. J., Dickie, I. A., Renton, M., Walker, C., Moot, D., et al. (2017). Fine root endophytes under scrutiny: a review of the literature on arbuscule-producing fungi recently suggested to belong to the Mucoromycotina. Mycorrhiza 27, 619-638. doi: 10.1007/s00572-017-0 $782-\mathrm{z}$

Ordoñez, Y. M., Fernandez, B. R., Lara, L. S., Rodriguez, A., Uribe-Vélez, D., and Sanders, I. R. (2016). Bacteria with phosphate solubilizing capacity alter mycorrhizal fungal growth both inside and outside the root and in the presence of native microbial communities. PLOS ONE 11:e0154438. doi: 10.1371/journal.pone. 0154438

Parks, D. H., Rinke, C., Chuvochina, M., Chaumeil, P. A., Woodcroft, B. J., Evans, P. N., et al. (2017). Recovery of nearly 8,000 metagenomeassembled genomes substantially expands the tree of life. Nat. Microb. 2:1533. doi: $10.1038 / s 41564-017-0012-7$ 
Partida-Martinez, L. P., Monajembashi, S., Greulich, K. O., and Hertweck, C. (2007). Endosymbiont-dependent host reproduction maintains bacterialfungal mutualism. Curr. Biol. 17, 773-777. doi: 10.1016/j.cub.2007. 03.039

Pawlowska, T. E., Gaspar, M. L., Lastovetsky, O. A., Mondo, S. J., Real-Ramirez, I., Shakya, E., et al. (2018). Biology of fungi and their bacterial endosymbionts. Annu. Rev. Phytopathol. 56, 289-309. doi: 10.1146/annurev-phyto-080417-045914

Pumplin, N., Zhang, X., Noar, R. D., and Harrison, M. J. (2012). Polar localization of a symbiosis-specific phosphate transporter is mediated by a transient reorientation of secretion. Proc. Natl. Acad. Sci. U.S.A. 109, E665-E672. doi: 10.1073/pnas.11102 15109

Ramírez-Flores, M. R., Rellán-Álvarez, R., Wozniak, B., Gebreselassie, M. N., Jakobsen, I., Olalde-Portugal, V., et al. (2017). Co-ordinated changes in the accumulation of metal ions in maize (Zea mays ssp. mays L.) in response to inoculation with the arbuscular mycorrhizal fungus Funneliformis mosseae. Plant Cell Physiol. 58, 1689-1699. doi: 10.1093/pcp/pcx100

Redecker, D., Hijri, I., and Wiemken, A. (2003). Molecular identification of arbuscular mycorrhizal fungi in roots: perspectives and problems. Folia Geobot. 38, 113-124. doi: 10.1007/BF02803144

Remy, W., Taylor, T. N., Hass, H., and Kerp, H. (1994). Four-hundred-million year-old vesicular-arbuscular mycorrhizae. Proc. Natl. Acad. Sci. U.S.A. 91, 11841-11843. doi: 10.1073/pnas.91.25.11841

Rich, M. K., Nouri, E., Courty, P. E., and Reinhardt, D. (2017). Diet of arbuscular mycorrhizal fungi: bread and butter? Trends Plant Sci. 22, 652-660. doi: 10.1016/j.tplants.2017.05.008

Rillig, M. C., Ramsey, P. W., Gannon, J. E., Mummey, D. L., Gadkar, V., and Kapulnik, Y. (2008). Suitability of mycorrhiza-defective mutant/wildtype plant pairs (Solanum lycopersicum L. cv Micro-Tom) to address questions in mycorrhizal soil ecology. Plant Soil 308, 267-275. doi: $10.1007 / \mathrm{s} 11104-008-9629-\mathrm{x}$

Rodriguez, A., and Sanders, I. R. (2015). The role of community and population ecology in applying mycorrhizal fungi for improved food security. ISME J. 9, 1053-1061. doi: 10.1038/ismej.2014.207

Rodríguez, H., and Fraga, R. (1999). Phosphate solubilizing bacteria and their role in plant growth promotion. Biotechnol. Adv. 17, 319-339. doi: 10.1016/S0734-9750(99)00014-2

Ropars, J., Toro, K. S., Noel, J., Pelin, A., Charron, P., Farinelli, L., et al. (2016). Evidence for the sexual origin of heterokaryosis in arbuscular mycorrhizal fungi. Nat. Microbiol. 1:16033. doi: 10.1038/nmicrobiol.2016.33

Rosendahl, S. (2008). Communities, populations and individuals of arbuscular mycorrhizal fungi. New Phytol. 178, 253-266. doi: $10.1111 / j .1469-8137.2008 .02378 . x$

Roth, R., and Paszkowski, U. (2017). Plant carbon nourishment of arbuscular mycorrhizal fungi. Curr. Opin. Plant Biol. 39, 50-56. doi: 10.1016/j.pbi.2017.05.008

Sanders, F. E., and Sheikh, N. A. (1983). The development of vesiculararbuscular mycorrhizal infection in plant root system. Plant Soil 71, 223-246. doi: $10.1007 /$ BF02182658

Sanders, I. R., Clapp, J. P., and Wiemken, A. (1996). The genetic diversity of arbuscular mycorrhizal fungi in natural ecosystems-a key to understanding the ecology and functioning of the mycorrhizal symbiosis. New Phytol. 133, 123-134. doi: 10.1111/j.1469-8137.1996.tb04348.x

Sanders, I. R., and Croll, D. (2010). Arbuscular mycorrhiza: the challenge to understand the genetics of the fungal partner. Annu. Rev. Genet. 44, 271-292. doi: 10.1146/annurev-genet-102108-134239

Sanders, I. R., and Rodriguez, A. (2016). Aligning molecular studies of mycorrhizal fungal diversity with ecologically important levels of diversity in ecosystems. ISME J. 10, 2780-2786. doi: 10.1038/ismej.2016.73

Sawers, R. J., Gebreselassie, M. N., Janos, D. P., and Paszkowski, U. (2010). Characterizing variation in mycorrhiza effect among diverse plant varieties. Theor. Appl. Genet. 120, 1029-1039. doi: 10.1007/s00122-009-1231-y

Sawers, R. J., Svane, S. F., Quan, C., Grønlund, M., Wozniak, B., Gebreselassie, M. N., et al. (2017). Phosphorus acquisition efficiency in arbuscular mycorrhizal maize is correlated with the abundance of root-external hyphae and the accumulation of transcripts encoding PHT1 phosphate transporters. New Phytol. 214, 632-643. doi: 10.1111/nph.14403
Sawers, R. J. H., Ramírez-Flores, M. R., Olalde-Portugal, V., and Paszkowski, U. (2018). The impact of domestication and crop improvement on arbuscular mycorrhizal symbiosis in cereals: insights from genetics and genomics. New Phytol. 220, 1135-1140. doi: 10.1111/nph.15152.

Sbrana, C., Strani, P., Pepe, A., de Novais, C. B., and Giovannetti, M. (2018). Divergence of Funneliformis mosseae populations over 20 years of laboratory cultivation, as revealed by vegetative incompatibility and molecular analysis. Mycorrhiza 28, 329-341. doi: 10.1007/s00572-018-0830-3

Schachtman, D. P., Reid, R. J., and Ayling, S. M. (1998). Phosphorus uptake by plants: from soil to cell. Plant Physiol. 116, 447-453. doi: 10.1104/pp.116.2.447

Schlaeppi, K., Bender, S. F., Mascher, F., Russo, G., Patrignani, A., Camenzind, T., et al. (2016). High-resolution community profiling of arbuscular mycorrhizal fungi. New Phytol. 212, 780-791. doi: 10.1111/nph.14070

Sedzielewska Toro, K. and Brachmann, A. (2016). The effector candidate repertoire of the arbuscular mycorrhizal fungus Rhizophagus clarus. BMC Genomics 17:101. doi: 10.1186/s12864-016-2422-y

Selosse, M. A., Vincenot, L., and Öpik, M. (2016). Data processing can mask biology: towards better reporting of fungal barcoding data? New Phytol. 210, 1159-1164. doi: 10.1111/nph.13851

Sharma, S. B., Sayyed, R. Z., Trivedi, M. H., and Gobi, T. A. (2013). Phosphate solubilizing microbes: sustainable approach for managing phosphorus deficiency in agricultural soils. SpringerPlus 2:587. doi: 10.1186/2193-1801-2-587

Smith, S. E., Jakobsen, I., Grønlund, M., and Smith, F. A. (2011). Roles of arbuscular mycorrhizas in plant phosphorus nutrition: interactions between pathways of phosphorus uptake in arbuscular mycorrhizal roots have important implications for understanding and manipulating plant phosphorus acquisition. Plant Physiol. 156, 1050-1057. doi: 10.1104/pp.111.174581

Smith, S. E., and Read, D. J. (2008). Mycorrhizal Symbiosis. 3rd ed. London: Academic Press Ltd.

Smith, S. E., and Smith, F. A. (2011). Roles of arbuscular mycorrhizas in plant nutrition and growth: new paradigms from cellular to ecosystem scales. Annu. Rev. Plant Biol. 62, 227-250. doi: 10.1146/annurev-arplant-042110-103846

Smith, S. E., Smith, F. A., and Jakobsen, I. (2004). Functional diversity in arbuscular mycorrhizal (AM) symbioses: the contribution of the mycorrhizal P uptake pathway is not correlated with mycorrhizal responses in growth or total $\mathrm{P}$ uptake. New Phytol. 162, 511-524. doi: 10.1111/j.1469-8137.2004.01039.x

Strom, N. B., and Bushley, K. E. (2016). Two genomes are better than one: history, genetics, and biotechnological applications of fungal heterokaryons. Fungal Biol. Biotechnol. 3:4. doi: 10.1186/s40694-016-0022-x

Svenningsen, N. B., Watts-Williams, S. J., Joner, E. J., Battini, F., Efthymiou, A., Cruz-Paredes, C., et al. (2018). Suppression of the activity of arbuscular mycorrhizal fungi by the soil microbiota. ISME J. 12, 1296-1307. doi: 10.1038/s41396-018-0059-3

Tamura, Y., Kobae, Y., Mizuno, T., and Hata, S. (2012). Identification and expression analysis of arbuscular mycorrhiza-inducible phosphate transporter genes of soybean. Biosci. Biotechnol. Biochem. 76, 309-313. doi: 10.1271/bbb.110684

Tang, N., San Clemente, H., Roy, S., Bécard, G., Zhao, B., and Roux, C. (2016). A survey of the gene repertoire of Gigaspora rosea unravels conserved features among Glomeromycota for obligate biotrophy. Front. Microbiol. 7:233. doi: $10.3389 /$ fmicb. 2016.00233

Tawaraya, K. (2003). Arbuscular mycorrhizal dependency of different plant species and cultivars. Soil Sci. Plant Nutr. 49, 655-668. doi: 10.1080/00380768.2003.10410323

Taylor, J. D., and Helgason, T., Öpik, M. (2017). "Molecular community ecology of arbuscular mycorrhizal fungi," in The Fungal Community: Its Organization and Role in the Ecosystem, eds J. Dighton, J. White, and P. Oudemans (Florida, FL: CRC Press), 3-26. doi: 10.1079/9781845930622.0000

Tisserant, E., Malbreil, M., Kuo, A., Kohler, A., Symeonidi, A., Balestrini, R., et al. (2013). Genome of an arbuscular mycorrhizal fungus provides insight into the oldest plant symbiosis. 2013: genome of an arbuscular mycorrhizal fungus provides insight into the oldest plant symbiosis. Proc. Natl. Acad. Sci. U.S.A. 111, 562-563. doi: 10.1073/pnas.1313452110

Torres-Cortés, G., Ghignone, S., Bonfante, P., and Schüßler, A. (2015). Mosaic genome of endobacteria in arbuscular mycorrhizal fungi: Transkingdom gene transfer in an ancient mycoplasma-fungus association. Proc. Natl. Acad. Sci. U.S.A. 112, 7785-7790. doi: 10.1073/pnas.1501540112 
Vályi, K., Mardhiah, U., Rillig, M. C., and Hempel, S. (2016). Community assembly and coexistence in communities of arbuscular mycorrhizal fungi. ISME J. 10, 2341-2351. doi: 10.1038/ismej.2016.46

van der Heijden, M. G., and Scheublin, T. R. (2007). Functional traits in mycorrhizal ecology: their use for predicting the impact of arbuscular mycorrhizal fungal communities on plant growth and ecosystem functioning. New Phytol. 174, 244-250. doi: 10.1111/j.1469-8137.2007.0 2041.x

van der Heijden, M. G. A., Dombrowski, N., and Schlaeppi, K. (2017). Continuum of root-fungal symbioses for plant nutrition. Proc. Natl. Acad. Sci. U.S.A. 114, 11574-11576. doi: 10.1073/pnas.1716329114

Van Geel, M., De Beenhouwer, M., Ceulemans, T., Caes, K., Ceustermans, A., Bylemans, D., et al. (2016). Application of slow-release phosphorus fertilizers increases arbuscular mycorrhizal fungal diversity in the roots of apple trees. Plant Soil 402, 291-301. doi: 10.1007/s11104-015-2 $777-\mathrm{x}$

van Tuinen, D., Jacquot, E., Zhao, B., Gollotte, A., and Gianinazzi-Pearson, V. (1998). Characterization of root colonization profiles by a microcosm community of arbuscular mycorrhizal fungi using 25S rDNA-targeted nested PCR. Mol. Ecol. 7, 879-887. doi: 10.1046/j.1365-294x.1998.0 0410.x

Vance, C. P. (2001). Symbiotic nitrogen fixation and phosphorus acquisition. Plant nutrition in a world of declining renewable resources. Plant Physiol. 127, 390-397. doi: 10.1104/pp.010331

Varela-Cervero, S., Vasar, M., Davison, J., Barea, J. M., and Öpik, M., AzcónAguilar, C. (2015). The composition of arbuscular mycorrhizal fungal communities differs among the roots, spores and extraradical mycelia associated with five Mediterranean plant species. Environ. Microb. 17, 2882-2895. doi: 10.1111/1462-2920.12810

Walder, F., and van der Heijden, M. G. (2015). Regulation of resource exchange in the arbuscular mycorrhizal symbiosis. Nat. Plants 1:15159. doi: 10.1038/nplants.2015.159

Walker, C., Gollotte, A., and Redecker, D. (2018). A new genus, Planticonsortium (Mucoromycotina), and new combination (P. tenue), for the fine root endophyte, Glomus tenue (basionym Rhizophagus tenuis). Mycorrhiza 28, 213-219. doi: 10.1007/s00572-017-0815-7

Wang, M., and Jin, H. (2017). Spray-induced gene silencing: a powerful innovative strategy for crop protection. Trends Microbiol. 25, 4-6. doi: 10.1016/j.tim.2016.11.011
Watts-Williams SJ Cavagnaro, T. R. (2015). Using mycorrhiza-defective mutant genotypes of non-legume plant species to study the formation and functioning of arbuscular mycorrhiza: a review. Mycorrhiza 25, 587-597. doi: 10.1007/s00572-015-0639-2

Willmann, M., Gerlach, N., Buer, B., Polatajko, A., and Nagy, R., Koebke, E. et al. (2013). Mycorrhizal phosphate uptake pathway in maize: vital for growth and cob development on nutrient poor agricultural and greenhouse soils. Front. Plant Sci. 4:533. doi: 10.3389/fpls.2013.00533

Xie, X., Lin, H., Peng, X., Xu, C., Sun, Z., Jiang, K., et al. (2016). Arbuscular mycorrhizal symbiosis requires a phosphate transceptor in the Gigaspora margarita fungal symbiont. Mol. Plant 9, 1583-1608. doi: 10.1016/j.molp.2016.08.011

Yang, S. Y., Grønlund, M., Jakobsen, I., Grotemeyer, M. S., Rentsch, D., Miyao, A., et al. (2012). Nonredundant regulation of rice arbuscular mycorrhizal symbiosis by two members of the PHOSPHATE TRANSPORTER1 gene family. Plant Cell 24, 4236-4251. doi: 10.1105/tpc.112.104901

Zhang, L., Fan, J., Ding, X., He, X., Zhang, F., and Feng, G. (2014). Hyphosphere interactions between an arbuscular mycorrhizal fungus and a phosphate solubilizing bacterium promote phytate mineralization in soil. Soil Biol Biochem. 74, 177-183. doi: 10.1016/j.soilbio.2014.03.004

Zhang, L., Feng, G., and Declerck, S. (2018). Signal beyond nutrient, fructose, exuded by an arbuscular mycorrhizal fungus triggers phytate mineralization by a phosphate solubilizing bacterium. ISME J. 12, 2339-2351. doi: 10.1038/s41396-018-0171-4

Zhang, L., Xu, M., Liu, Y., Zhang, F., Hodge, A., and Feng, G. (2016). Carbon and phosphorus exchange may enable cooperation between an arbuscular mycorrhizal fungus and a phosphate-solubilizing bacterium. New Phytol. 210, 1022-1032. doi: $10.1111 /$ nph. 13838

Conflict of Interest Statement: The author declares that the research was conducted in the absence of any commercial or financial relationships that could be construed as a potential conflict of interest.

Copyright (C) 2019 Kobae. This is an open-access article distributed under the terms of the Creative Commons Attribution License (CC BY). The use, distribution or reproduction in other forums is permitted, provided the original author $(s)$ and the copyright owner(s) are credited and that the original publication in this journal is cited, in accordance with accepted academic practice. No use, distribution or reproduction is permitted which does not comply with these terms. 